AperTO - Archivio Istituzionale Open Access dell'Università di Torino

\title{
Data sharing and interoperability: Fostering innovation and competition through APIs
}

\section{This is a pre print version of the following article:}

Original Citation:

Availability:

This version is available http://hdl.handle.net/2318/1703780

since 2019-05-31T20:58:53Z

Published version:

DOI:10.1016/j.clsr.2019.03.008

Terms of use:

Open Access

Anyone can freely access the full text of works made available as "Open Access". Works made available under a Creative Commons license can be used according to the terms and conditions of said license. Use of all other works requires consent of the right holder (author or publisher) if not exempted from copyright protection by the applicable law. 


\section{Stanford - Vienna \\ Transatlantic Technology Law Forum \\ A joint initiative of \\ Stanford Law School and the University of Vienna School of Law}

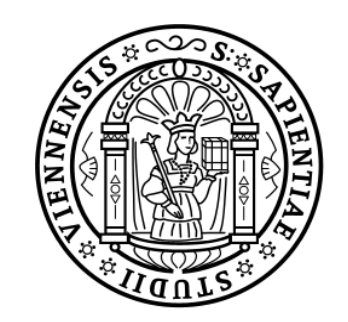

\section{European Union Law Working Papers}

No. 38

Data Sharing and Interoperability Through APIs: Insights from European Regulatory Strategy

Oscar Borgogno \& Giuseppe Colangelo 


\section{European Union Law Working Papers}

Editors: Siegfried Fina and Roland Vogl

About the European Union Law Working Papers

The European Union Law Working Paper Series presents research on the law and policy of the European Union. The objective of the European Union Law Working Paper Series is to share "works in progress". The authors of the papers are solely responsible for the content of their contributions and may use the citation standards of their home country. The working papers can be found at http://ttlf.stanford.edu.

The European Union Law Working Paper Series is a joint initiative of Stanford Law School and the University of Vienna School of Law's LLM Program in European and International Business Law.

If you should have any questions regarding the European Union Law Working Paper Series, please contact Professor Dr. Siegfried Fina, Jean Monnet Professor of European Union Law, or Dr. Roland Vogl, Executive Director of the Stanford Program in Law, Science and Technology, at:

\section{Stanford-Vienna Transatlantic Technology Law Forum http://ttlf.stanford.edu}

Stanford Law School

Crown Quadrangle

559 Nathan Abbott Way

Stanford, CA 94305-8610
University of Vienna School of Law

Department of Business Law Schottenbastei 10-16 1010 Vienna, Austria 


\begin{abstract}
About the Authors
Oscar Borgogno is currently pursuing a Ph.D. in Law, Persons, and Markets at the University of Turin, Italy, and a MSc in Law and Finance at the University of Oxford, UK. In 2018, he was a Research Fellow at the Tilburg Institute for Law, Technology, and Society, University of Tilburg, Netherlands.

He graduated in Law from the University of Turin and attended the Ferdinando Rossi School of Advanced Studies at the University of Turin.

His primary research interests are competition law, data regulation, and financial markets regulation.

Giuseppe Colangelo is a Jean Monnet Professor of European Innovation Policy and Associate Professor of Law and Economics at University of Basilicata, Italy. He is also Adjunct Professor of Markets, Regulation and Law, and of Legal Issues in Marketing at LUISS Guido Carli and Bocconi University, Italy.

He graduated in Law from LUISS Guido Carli, earned an LL.M. in Competition Law and Economics at the Erasmus University of Rotterdam, Netherlands, and a Ph.D. in Law and Economics at LUISS Guido Carli.

His primary research interests are related to innovation policy, intellectual property, competition policy, market regulation, and economic analysis of law.

Giuseppe has been a TTLF Fellow since 2017.
\end{abstract}

\title{
General Note about the Content
}

The opinions expressed in this paper are those of the authors and not necessarily those of the Transatlantic Technology Law Forum or any of its partner institutions, or the sponsors of this research project.

\section{Suggested Citation}

This European Union Law Working Paper should be cited as:

Oscar Borgogno \& Giuseppe Colangelo, Data Sharing and Interoperability Through APIs: Insights from European Regulatory Strategy, Stanford-Vienna European Union Law Working Paper No. 38, http://ttlf.stanford.edu.

\section{Copyright}

(C) 2018 Oscar Borgogno \& Giuseppe Colangelo 


\begin{abstract}
Application Programming Interfaces (APIs) have been identified by the European Commission as a key enabler of interoperability among private and public undertakings. Moreover, a systematic adoption of open and standardized APIs by firms and developers appears to be crucial for unlocking competition and promoting the flourishing of Artificial Intelligence (AI) and Internet of Things (IoT) innovation.

An analysis of the main European regulatory initiatives which have so far surfaced in the realm of data governance (right to personal data portability, free flow of nonpersonal data, access to customer account data rule, re-use of government data) reveals that the EU legislature is not tackling the matter consistently. While all of these initiatives share a reliance on APIs for the facilitation of a sound and effective data sharing ecosystem, they vary in terms of rationale, scope and implementation. Furthermore, data sharing via APIs requires a complex implementation process, and technicalities are crucial for their success. Moreover, an excessive reliance on fair, reasonable and non-discriminatory (FRAND) terms might be overestimated when it comes to data compensation, as has been demonstrated by the continuing saga involving standard essential patents.
\end{abstract}

Keywords: big data, Artificial Intelligence, Internet of Things, data portability, API, standards, regulation, competition policy.

JEL Codes: K21, K22, K23, L15, L50 


\section{Contents}

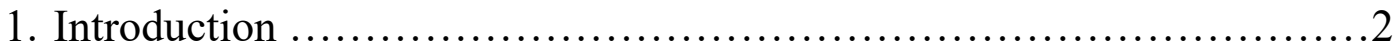

2. The manifold forms of data sharing and the role of APIs $\quad \ldots \ldots \ldots \ldots \ldots 7$

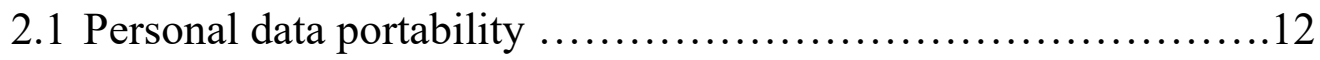

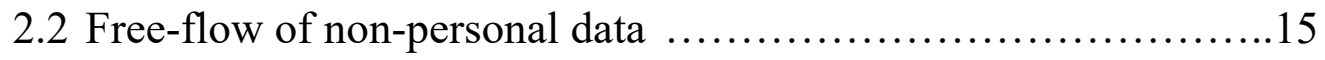

2.3 Account data portability ................................... 19

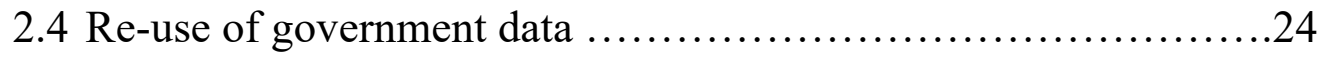

2.5 The risk of regulatory inconsistencies $\ldots \ldots \ldots \ldots \ldots \ldots \ldots \ldots \ldots . . \ldots \ldots$

3. Some lessons from antitrust to address data sharing $\ldots \ldots \ldots \ldots \ldots \ldots \ldots . . \ldots 29$

3.1 The limits of competition law enforcement $\quad$...................30

3.2 The role of standardization $\quad$................................33

3.3 Are FRAND terms a solution? ................................37

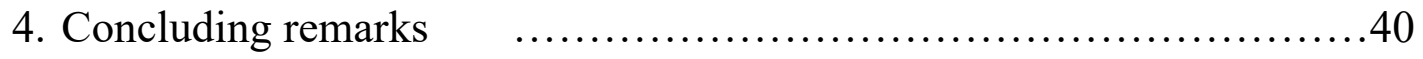




\section{Introduction}

In July 2018 four tech giants, namely Microsoft, Google, Twitter and Facebook, announced the launch of a joint open-source initiative, called the Data Transfer Project, with the objective of easing user data transfer among their platforms. ${ }^{1}$ According to the declarations, this new data portability mechanism will remove the infrastructure burden on providers and users related to the portability of data from one company to another: "[T]he future of portability will need to be more inclusive, flexible, and open. We believe users should be able to seamlessly and securely transfer their data directly from one provider to another."2 This initiative demonstrates that data portability has become a key concern for major market players ("data portability and interoperability are central to innovation"), ${ }^{3}$ who have now decided to address the calls recently made by the European Commission for Open Data policies. $^{4}$

There is no doubt that data analytics tools are essential to optimize mechanisms and complex decision processes, and thereby allowing firms to thrive by extracting value from information and delivering tailored services with significant added value for consumer welfare. Accordingly, the free movement of data has emerged as a new building block of European policy, laying the foundation for the development of new innovations based on

\footnotetext{
${ }^{1}$ Google Open Source Blog, 'Introducing Data Transfer Project: an open source platform promoting universal data portability' (2018) <https://opensource.googleblog.com/2018/07/introducing-data-transfer-project.html> accessed 4 September 2018; C. Shank, 'Microsoft, Facebook, Google and Twitter Introduce the Data Transfer Project: An Open Source Initiative for Consumer Data Portability' (2018) $<$ https://blogs.microsoft.com/eupolicy/2018/07/20/microsoft-facebook-google-and-twitter-introduce-the-datatransfer-project-an-open-source-initiative-for-consumer-data-portability/> accessed 4 September 2018.

2 Facebook, Google, Microsoft, and Twitter, 'Data transfer Project', White Paper (2018) 4, $<$ https://datatransferproject.dev/> accessed 4 September 2018.

${ }_{3}^{3}$ Facebook, Google, Microsoft, and Twitter (n 2 ) 3.

${ }^{4}$ European Commission, 'Towards a thriving data-driven economy' (Communication) COM (2014) 442 final, 5; European Commission, ‘Building a European Data Economy' (Communication) COM (2017) 9 final, 11.
} 
big data exploitation, such as Artificial Intelligence (AI) and the Internet of Things (IoT). ${ }^{5}$ AI environments are inherently dependent on data as an essential raw material, particularly with regards to machine learning and deep learning. ${ }^{6}$ Since AI functioning is based on the identification of patterns in available datasets and the subsequent making of predictions and correlations in order to solve technical problems, the availability of large amounts of information is crucial to its functioning. ${ }^{7}$ Hence, emerging technologies need continuous access to streams of data from several sources, generated by machines and connected devices.

The dependence of IoT and AI applications on an enormous diversity of data sources and types requires format standardization, an efficient system for personal information management, and serious efforts to ensure interoperability. Indeed, IoT hinges on standard and interoperable communication protocols which allow for a dynamic global network infrastructure consisting of physical and virtual 'things' (such as traditional and autonomous vehicles, mobile phones, home devices, and so on). ${ }^{8}$ These devices are integrated by means of intelligent interfaces and create smart environments where each item is able to interact in order to improve its own usefulness.

\footnotetext{
${ }^{5}$ European Commission, 'Building a European Data Economy' (n 4) 8.

${ }^{6}$ See D. Harhoff, S. Heumann, N. Jentzsch and P. Lorenz, 'Outline for a German Strategy for Artificial Intelligence', (2018) 14-18, <https://ssrn.com/abstract=3222566> accessed 4 September 2018, arguing that an AI strategy also requires a data strategy. See also I.M. Cockburn, R. Henderson, and S. Stern, 'The Impact of Artificial Intelligence on Innovation', in A.K. Agrawal, J. Gans, and A. Goldfarb (eds.), The Economics of Artificial Intelligence (University of Chicago Press, 2019), advocating the proactive development of institutions and policies that encourage competition, data sharing, and openness as an important determinant of economic gains from the development and application of deep learning: indeed, because the performance of deep learning algorithms depends on the training data that they are created from, barriers to data sharing could result in a balkanization of data within each sector, not only reducing innovative productivity within the sector, but also reducing spillovers back to the deep learning general purpose technologies sector, and to other application sectors.

7 European Commission, 'Artificial Intelligence for Europe', (Communication) COM (2018) 237 final, 4; European Commission, 'Towards a common European data space' (Communication) COM (2018) 232 final, 2-3.

8 PWC, 'Cross-Cutting Business Models for IoT', (2017) 2-3, <https://ec.europa.eu/digital-singlemarket/en/news/cross-cutting-business-models-internet-things-iot> accessed 6 September 2018.
} 
A key factor in the success of these cross-sector applications is the openness, according to agreed semantic models, of the transferable data .9 Therefore, data infrastructures capable of gathering and streaming a vast array of data as a sort of modern pipeline are going to be crucial for the IoT to flourish. ${ }^{10}$ EU firms need to be intensive data users in order to play an active role in these data-driven markets, but nowadays only $6.3 \%$ of European undertakings are able to proactively engage in such a new environment. ${ }^{11}$

It should come as no surprise, therefore, that access to data and related data sharing practices have recently gained attention among policy makers as a crucial factor in unlocking competition and enabling innovation to flourish. With the European Data Economy initiative, the European Commission has made clear its intention to nurture the development of the data-driven economy by encouraging the sharing and reusing of data within the Internal Market. ${ }^{12}$ This initiative is linked to the European Parliament's recent Regulation on the free flow of non-personal data in the EU, which aims at ensuring that no physical or legal barriers will hinder the development of the European data economy. ${ }^{13}$ In short, European policy makers are acknowledging the important function that massive data exploitation is going to have in the rise of both IoT and AI applications. ${ }^{14}$ As data-enabled

\footnotetext{
${ }^{9}$ Deloitte, 'Study on emerging issues of data ownership, interoperability, (re-)usability and access to data, and liability', (2017) 6, <https://ec.europa.eu/digital-single-market/en/news/study-emerging-issues-dataownership-interoperability-re-usability-and-access-data-and> accessed 6 September 2018.

${ }^{10} \mathrm{H}$. Varian, 'Artificial Intelligence, Economics, and Industrial Organization', (2018) NBER Working Paper 24839, $7<$ <ttp://www.nber.org/papers/w24839> accessed 4 September 2018.

${ }^{11}$ IDC and Open Evidence, 'European Data Market Study', (2017) $75<\underline{\text { https://ec.europa.eu/digital-single- }}$ market/en/news/final-results-european-data-market-study-measuring-size-and-trends-eu-data-economy> accessed 6 September 2018.

${ }^{12}$ European Commission, 'Towards a common European data space' (n 7).

${ }^{13}$ Regulation of the European Parliament and of the Council on a framework for the free-flow of non-personal data in the European Union (not yet published in the Official Journal). See Recitals 1 and 9 acknowledging that the rapid development of the data economy and emerging technologies are raising novel legal issues surrounding questions of access to and reuse of data and that the expanding Internet of Things, artificial intelligence and machine learning, represent major sources of non-personal data.

${ }^{14}$ European Commission, 'Guidance on sharing private sector data in the European data economy' (Staff Working Document) SWD (2018) 125 final, 1.
} 
services hold the promise of strengthening competition and boosting innovation in both existing and newly arising markets, there is room for customers and businesses to benefit considerably from a data-driven economy.

So far, regulatory interventions have focused on fostering as much data-driven innovation as possible by means of differing tools that work toward the same goal, namely the strengthening of competition through data sharing. This goal faces opposition, as firms holding large data pools are reluctant to share this value asset with actual or potential competitors. Additionally, concerns about confidentiality and trade secrets are likely to raise high barriers which may jeopardize the development of a common data space. ${ }^{15}$ The European Commission has already started to tackle these issues with a broad array of different legislative initiatives. While the General Data Protection Regulation (GDPR) introduced a general scope data portability right, ${ }^{16}$ the Second Payment Service Directive (PSD2) enshrined a sector-specific access to account data rule, ${ }^{17}$ and the recent Regulation on free-flow of non-personal data addresses data sharing practices in the commercial arena (business-to-business). Moreover, the Commission has introduced a proposal aimed at promoting the re-use of government data. ${ }^{18}$ Such a wide range of initiatives creates the risk of legal uncertainty for merchants and consumers. ${ }^{19}$

\footnotetext{
15 I. Graef, M. Husovec, and N. Purtova, 'Data Portability and Data Control: Lessons for an Emerging Concept in E.U. Law', (2017) TILEC Discussion Paper No. 2017-041, 10 $<$ https://papers.ssrn.com/sol3/papers.cfm?abstract id=3071875> accessed 4 September 2018.

16 Regulation (EU) 2016/679 of the European Parliament and of the Council of 27 April 2016 on the protection of natural persons with regard to the processing of personal data and on the free movement of such data, and repealing Directive 95/46/EC [2016] OJ L119/1, Art. 20.

17 Directive (EU) 2015/2366 of the European Parliament and of the Council of 25 November 2015 on payment services in the internal market, amending Directives 2002/65/EC, 2009/110/EC and 2013/36/EU and Regulation (EU) No 1093/2010, and repealing Directive 2007/64/EC, [2015] OJ L337, Art. 67.

${ }^{18}$ European Commission, 'Proposal for a Directive on the re-use of public sector information', $\mathrm{COM}(2018)$ 234 final.

${ }^{19}$ Graef, Husovec, and Purtova (n 15) 24.
} 
Against this background, Application Programming Interfaces (APIs) have surfaced as a technical tool capable of ensuring a smooth flow of data between undertakings. They are sets of protocols which define how software components communicate with one another. By allowing a firm to easily access the data gathered by another company, APIs can strengthen interoperability among different players and facilitate the exchange of data streams or datasets between data holders. Despite their clear pro-competitive potential, there is no consensus regarding who should define the APIs or, even more importantly, whether to standardize their creation. To avoid such a risk, the EU institutions have encouraged companies across the Internal Market to consider using open, standardized and well-documented APIs more broadly. This could include making data available in machinereadable formats and the provision of associated metadata.

In light of this development, two main points merit investigation. First, the regulatory approach adopted by the EU reflects the idea that the antitrust enforcement toolbox is inadequate to tackle effectively the need to ensure access to data. The scope of competition law is limited by the fact that it can be invoked only to gain access to a dataset held by a dominant firm, on a case-by-case basis. Furthermore, access can be imposed under antitrust law only if a refusal to grant access is considered abusive and if the resource at issue is considered essential according to the requirements established by case law. Second, even though API standardization is going to play a key role with reference to data access, we intend to sound a note of caution against the expectation that fair, reasonable and nondiscriminatory (FRAND) terms could ensure a smooth access to data avoiding litigation 
among data holders and access seekers. ${ }^{20}$ Conversely, it is worth evaluating the ongoing implementation process under PSD2 of the access-to-account rule, as it is at an advanced stage and might provide a useful lesson on how to design sector-specific regulation mandating a workable access to data.

The aim of this article is twofold. First, it aims to provide an overview of the main initiatives undertaken to enable access to data throughout the Internal Market and highlight the key role that APIs will play in this landscape. Second, drawing on the well-established antitrust literature on standardization and licensing practices, the paper will shed light on concerns and risks that could jeopardize the free movement of data. In this context, Section 2 will focus on the most relevant data portability tools envisaged by the European Union, namely the data portability right under the GDPR, the access-to-account rule under the PSD2, the attempt to regulate free-flow of non-personal data and the re-use of government data. Section 3 will address the relationship between antitrust enforcement and the regulatory interventions mandating data sharing. Section 4 will conclude with recommendations aimed at designing a sound standardization framework based on a sectorspecific approach tailored to the needs of the new API economy.

\section{The manifold forms of data sharing and the role of APIs}

Any debate on data sharing and the possible ways to implement it effectively cannot ignore the crucial role that APIs are going to play across the whole spectrum of digital society. ${ }^{21}$

\footnotetext{
20 See European Commission, 'Building a European Data Economy' (n 4) 13; European Commission, 'FinTech Action plan: For a more competitive and innovative European financial sector' (Communication) COM (2018) 109 final, 7.

${ }^{21}$ European Commission, 'Guidance on sharing private sector data in the European data economy' (n 14) 8.
} 
APIs can be defined in broad terms as software tools designed to enable communication between two computer applications. ${ }^{22}$ Through a set of protocols and routines, they allow a digital application to interact with an associated program by describing the kind of data that can be retrieved, how to accomplish the data retrieval, and the format in which information will be filed. These interfaces have different levels of complexity, such as simple links to databases or specific datasets, web getaways and more detailed set-ups. APIs are not only pieces of software, but they come with a contract that enshrines the terms and conditions of the license, and outlines how the interfaces can be used by developers.

APIs offer a twofold advantage in terms of data sharing within and across companies. First, APIs set up a metering system of access to data held in a specific database or server, empowering providers with a sort of smart gateway to their data. Second, depending on whether they are closed or open, APIs represent the building blocks of modular industrial architecture and platform business models respectively. ${ }^{23}$ Closed (or internal) APIs are accessible only to those working within a firm. Companies use them because they enhance internal integration and speedy data sharing among different departments and employee teams. Indeed, a systematic and smooth sharing of data within a firm improves productivity by fostering better exploitation of internal data streams and optimizing existing processes. ${ }^{24}$ Open (or external) APIs, on the contrary, are aimed at enabling integration with third parties (such as partners, external developers or even competitors) by allowing them to

\footnotetext{
${ }^{22}$ For a technical overview on the structure, functioning, and business impact of APIs, see G. Benzell, G. Lagarda, and M. Van Alstyne, 'The Impact of APIs on Firm Performance', (2017) Boston University Questrom School of Business Research Paper No. 2843326, <https://ssrn.com/abstract=2843326> accessed 8 September 2018; M. Zachariadis and P. Ozcan, 'The API Economy and Digital Transformation in Financial Services: The Case of Open Banking', (2017) SWIFT Institute Working Paper No. 2016-001, $<$ https://swiftinstitute.org/wp-content/uploads/2017/07/SIWP-2016-001-Impact-Open-APIs-FINAL.pdfs accessed 8 September 2018.

${ }^{23}$ Zachariadis and Ozcan (n 22) 6.

${ }^{24}$ Benzell, Lagarda, and Van Alstyne (n 22) 6.
} 
access specific datasets. Such external interfaces are at the very heart of interoperability and modularity, both of which characterize the modern business platform models. ${ }^{25}$

By allowing for data sharing and interoperability with third parties, open APIs lead to upselling as well as cross-selling opportunities; this allows digital marketplace environments to flourish down the line. Further, APIs provide a scalable mechanism of governance and platform management, thereby ensuring, to the benefit of the platform owner, control as well as monetization. The monetization opportunities of APIs vary widely depending on the business method enacted by the provider. Furthermoe, the potential copyrightability of APIs could further strengthen the proprietary rights of API owners. ${ }^{26}$ Owing to all these features, the adoption of APIs generates decreases in operating costs as well as increases in sales, market capitalization, intangible assets, and net income. ${ }^{27}$ Thus, it is not surprising that nowadays some of the most valuable companies in the world, such as Google, Microsoft and Apple, all share a platform ecosystem model based on external communities of developers. ${ }^{28}$

With regard to the interoperability of digital interactive television services, the European authorities stated as long ago as 2002 that the migration from existing APIs to new open APIs should be encouraged and facilitated. ${ }^{29}$ Hence, they invited Member States to

\footnotetext{
${ }^{25}$ Benzell, Lagarda, and Van Alstyne (n 22) 3.

${ }^{26}$ On the on-going debate taking place in the US with reference to APIs' copyrightability in the aftermath of Oracle America, Inc. v. Google LLC, 886 F3d 1179 (2018 Fed. Cir.), see P.S. Menell, 'Rise of the API Copyright Dead: An Updated Epitaph for Copyright Protection of Network and Functional Features of Computer Software', (2018) 31 Harvard Journal of Law \& Technology 305.

${ }^{27}$ Benzell, Lagarda, and Van Alstyne (n 22) 32.

${ }^{28}$ G. Parker, M. Van Alstyne, and X. Jiang, 'Platform Ecosystems: How Developers Invert the Firm', (2016) Boston University Questrom School of Business Research Paper No. 2861574, 1, $<$ http://ide.mit.edu/sites/default/files/publications/Platform\%20Ecosystems\%20How\%20Developers\%20Invert\%20the\%20Frim.pdf $>$ accessed 8 September 2018.

${ }^{29}$ Directive 2002/21/EC on a common regulatory framework for electronic communications networks and services (Framework Directive), Recital 31, [2002] OJ L108/33.
} 
"encourage proprietors of APIs to make available on fair, reasonable and nondiscriminatory terms, and against appropriate remuneration, all such information as is necessary to enable providers of digital interactive television services to provide all services supported by the API in a fully functional form." ${ }^{\prime 30}$ However, it must be acknowledged that the increasing number and heterogeneity of market players is likely to lead to conflicts of interest among platform owners and third-party developers which could lead to litigations and exclusionary or exploitative behaviors. ${ }^{31}$ In this respect, APIs can be deployed to engage in anti-competitive practices to the detriment of newcomers or, conversely, to control the platform and ensure an effective level of regulatory predictability by the owner. ${ }^{32}$ Depending on how platform owners make use of their open APIs, they can limit or foster access to the relevant APIs or even carry out discriminatory practices.

Among EU policy makers, the necessity of ensuring interoperability of datasets for a thriving data-driven economy has attracted interest since the European Council's conclusions of October 2013, which focused on the digital economy, innovation and services as drivers for growth and jobs. ${ }^{33}$ Notably, in 2014 the European Commission started advocating the adoption of standardized and "shared formats and protocols for gathering and processing data from different sources in a coherent and interoperable manner across sectors and vertical markets. ${ }^{.34}$ More recently, the European Commission has begun to "explore a possible future EU framework for data access." 35 The underlying

\footnotetext{
${ }^{30}$ Directive 2002/21/EC (n 30) Article 18(2).

31 Zachariadis and Ozcan (n 22) 8.

32 Zachariadis and Ozcan (n 22) 8.

33 European Council, 'Conclusions of the European Council (24/25 October 2013)' EUCO 169/13, 4.

34 European Commission, 'Towards a thriving data-driven economy' (n 4) 6. See also M.S. Gal and D. Rubinfeld, 'Data Standardization', mimeo, arguing that, since not all data are alike, standardization of data semantics, attributes, structure, formats, or interfaces is needed in order to facilitate interoperability.

${ }^{35}$ European Commission, ‘Building a European Data Economy' (n 4) 11.
} 
goal of such a far-reaching initiative is to establish a pro-competitive environment where the sharing, aggregation and reuse of machine-generated data could be a source of new business models, in addition to "making relevant data available for training AI applications." ${ }^{\prime 36}$ Against this background, APIs' architecture and design has been identified as a crucial element for a flourishing common European data space. Consequently, the Commission has envisaged the adoption of a "broader use of open, standardized and welldocumented APIs ... through technical guidance, including identification and spreading of best practice for companies and public sector bodies." 37 Moreover, the Commission has launched an assessment process aimed at deciding how best to encourage undertakings to adopt "open, standardized and well-documented APIs."38

As already mentioned, the European Commission has started to tackle the issues of data sharing and interoperability with a broad array of legislative initiatives aimed at promoting data portability. Indeed, data interoperability considerations are closely related to questions of data portability, since "effective portability policies must be supported by appropriate technical standards in order to implement meaningful portability in a technologically neutral manner." 39 Therefore, it is worth carrying out a comparison of the major European legislative attempts to enact data sharing regimes in order to evaluate whether and how they can effectively help to achieve the ambitious goal of a common data space.

\footnotetext{
${ }^{36}$ European Commission, ‘Towards a common European data space' (n 7) 10.

${ }^{37}$ European Commission, 'Building a European Data Economy' (n 4) 12.

${ }^{38}$ European Commission, 'Guidance on sharing private sector data in the European data economy' (n 14$) 8$.

${ }^{39}$ European Commission, 'Building a European Data Economy' (n 4) 16.
} 


\subsection{Personal data portability}

The right to data portability enacted by the GDPR has been praised as a complete novelty within the EU data protection landscape ${ }^{40}$ Leaving aside the access-to-account rule under the PSD2, no attempt to enact a similar regulatory initiative has been pursued before. ${ }^{41}$ In fact, this innovation can be read as the first complement to the Digital Single Market Strategy launched by the European Commission in $2015 .{ }^{42}$ Moreover, as a substantial part of the data flowing throughout the Internal Market is personal data (according to the broad definition set forth in the GDPR), such a regime is a cornerstone of the European data common space. ${ }^{43}$

In essence, with this legislative instrument the EU seeks to empower individuals by granting them more control over their personal data. ${ }^{44}$ The right to data portability aims at enabling a smooth data transfer process from one data controller to the other by means of a threefold structure. More specifically, pursuant to Article 20 of the GDPR, the right to data portability consists of three different rights granted to the data subject, namely the right to receive a copy of the data provided to the data controller, the right to transmit those data to

\footnotetext{
${ }^{40}$ As pointed out in P. De Hert, V. Papakonstantinou, G. Malgieri, L. Baslay, and I. Sanchez, 'The right to data portability in the GDPR: Towards user-centric interoperability of digital services' (2018) 34 Computer Law and Security Review 193, 194, the closest theoretical precursor of data portability is the number portability enshrined in the Article 30 of the Directive 2002/22/EC on universal service and users' rights relating to electronic communications networks and services.

${ }^{41}$ B. Custers and H. Ursic, 'Big Data and Data Reuse: a taxonomy of data reuse for balancing big data benefits and personal data protection' (2016) 6 International Data Privacy Law 4, 9.

${ }^{42}$ European Commission, 'A Digital Single Market Strategy for Europe' (Communication) COM (2015) 192 final, 14.

${ }^{43}$ GDPR (n 16) Article 4.

44 Article 29 Data Protection Working Party, "Guidelines on the right to 'data portability" (2017), 2, $<\mathrm{http} / / /$ ec.europa.eu/newsroom/article29/item-detail.cfm?item_id=611233> accessed 9 September 2018; GDPR (n 16) Recital 68. See also G. Colangelo and M. Maggiolino, 'Fragile or Smart Consumers? Suggestions for the US from the EU' (2018) Stanford-Vienna TTLF Working Paper No. 36, 8-9, $<$ https://papers.ssrn.com/sol3/papers.cfm?abstract_id=3228376> accessed 10 September 2018.
} 
another controller and the right to request a direct transfer from one controller to another. ${ }^{45}$ The first two rights can be freely exercised (provided that the processing is based on consent or on a contract and is carried out by automated means). Conversely, the third is dependent on its technical feasibility, meaning the interoperability of the systems involved. ${ }^{46}$ Furthermore, since these rights are within the general scope of the GDPR, every controller is obliged to comply with them regardless of its size, the reasons for which portability is sought or the scale of its processing activity.

In addition, by affirming individuals' control over their personal data, data portability is expected to tackle personal data lock-in problems, 're-balance' the relationship between data subjects and data controllers (i.e., between digital consumers and digital platforms), and encourage competition between companies. ${ }^{47}$ Indeed, the rationale for the data portability right fits better within a competition policy framework than it does within the traditional data protection systems founded on Article 8 of the EU Charter of Fundamental Rights. Customer empowerment by means of individual control over personal data has the potential to unlock competition within data-driven markets. ${ }^{48}$ Thus, the main goal underpinning data portability is the promotion of competition among data-enabled service providers rather than the creation of a form of default ownership by personal data

\footnotetext{
${ }^{45}$ GDPR (n 16) Article 20.

${ }^{46}$ GDPR (n 16) Recital 68.

${ }^{47}$ Article 29 Data Protection Working Party (n 44) 4. See also European Commission, 'Stronger protection, new opportunities - Commission guidance on the direct application of the General Data Protection Regulation as of 25 May 2018', (Communication) COM (2018) 43 final.

${ }^{48}$ O. Lynskey, 'Aligning data protection rights with competition law remedies? The GDPR right to data portability', (2017) European Law Review 793, 803. See also V. Kathuria and J.C. Lai, 'User Review Portability: Why and How?' (2018) TILEC Discussion Paper No. 2018-023, $<$ https://ssrn.com/abstract=3203344> accessed 10 September 2018, exploring the possibility of porting user reviews in order to enhance the competition among e-commerce platforms.
} 
subjects. ${ }^{49}$ A proper data portability remedy stemming from competition law, however, would be different, as it would apply to all (personal and not personal) data held by dominant firms on a case-by-case basis.

As it stands, the right to personal data portability is likely to prove problematic with regard to its implementation. In fact, Article 20(1) of the GDPR does not provide detailed guidance on how to ensure data portability among undertakings. It merely states a general requirement for the format of transmitted data, which need to be "structured, commonly used and machine readable." Further, any attempt to mandate the adoption of interoperable standards is excluded, as Recital 68 does not go beyond a simple "encouragement". Such lack of any binding provision or detailed guideline covering the implementation of data portability is likely to raise serious concerns about effectiveness and legal certainty. Interoperability and portability need to be made effective, otherwise they will remain a dead letter. ${ }^{50}$ For its part, the WP29 advisory group suggested the adoption of APIs to implement data portability with a sector-specific approach. ${ }^{51}$ However, nothing is mentioned with reference to their structure (open or closed), potential standardization attempts or terms and conditions of the license. ${ }^{52}$

The major risk stemming from this light-touch regulatory approach is an inconsistent development of personal data portability throughout the market, which could ultimately

\footnotetext{
${ }^{49}$ In fact, property would entail the right to exclude anyone, which is not provided by the right to data portability under the GDPR. Similarly, the right to erasure under the GDPR (Article 17) cannot be considered a proprietary tool, due to its extremely limited (and highly contested) applicability. On this point, see Graef, Husovec, and Purtova (n 15) 24. Instead, for a view supporting a proprietary setting, see De Hert, Papakonstantinou, Malgieri, Baslay, Sancez, (n 40) 201.

50 O. Borgogno and C. Poncibò, 'The Day After Tomorrow of Banking - On FinTech, Data Control and Consumer Empowerment' (2018) <https://www.law.ox.ac.uk/business-law-blog/blog/2018/04/law-andautonomous-systems-series-day-after-tomorrow-banking-fintech> accessed 9 September 2018.

${ }^{51}$ Article 29 Data Protection Working Party (n 44) 17.

52 Admittedly, Article 29 Data Protection Working Party (n 44) 17, states only that "formats that are subject to costly licensing constraints will not be considered an adequate approach."
} 
hinder the development of a European common data space. In fact, even though some sectors are already at an advanced stage in providing applications for transferring data, other market players might struggle to keep pace with such development when no open interoperability standards are yet available. ${ }^{53}$ The Data Transfer Project launched by Microsoft, Google, Twitter and Facebook explicitly promises to smooth the movement of data among service providers, but minor competitors or small firms are likely to lose further ground in the battle for the data as a direct consequence of the tech giants' efforts. ${ }^{54}$ In fact, without a serious and detailed open standardization effort, business costs arising from data portability compliance might jeopardize competition rather than enable it to thrive. Moreover, leaving market players completely free to adopt poorly secured and flawed APIs can lead to massive data breaches and open the gate to cybersecurity attacks, as demonstrated by the Cambridge Analytica scandal. ${ }^{55}$

\subsection{Free-flow of non-personal data}

As part of its general strategy, the European Commission took a further step in the direction of building a common data space by targeting the free flow of non-personal data through a specific regulation proposal. ${ }^{56}$ It is predicted that this legislative tool, together with the GDPR, will complete a comprehensive and coherent EU framework that enables free movement of data in the single market.

\footnotetext{
${ }^{53}$ Lynskey (n 48) 807.

${ }^{54}$ Facebook, Google, Microsoft, and Twitter (n 2) 3.

55 P.P. Polański, 'Some thoughts on data portability in the aftermath of the Cambridge Analytica scandal' (2018) 7 Journal of European Consumer and Market Law 4, 141.

56 European Commission, 'Proposal for a Regulation of the European Parliament and of the Council on a framework for the free-flow of non-personal data in the European Union' COM (2017) 495 final.
} 
The core objective of the Regulation is threefold. First and foremost, it introduces what can be considered the fifth freedom in addition to the four traditional ones (involving citizens, goods, services and capital), namely the free movement of data within the Union. ${ }^{57}$ Accordingly, apart from restrictions justified on public security grounds, Member States would lose the power to oblige undertakings to process or locate data within their borders by setting, for instance, data localization requirements. At the same time, such provisions would not affect the principle of data availability for regulatory control, which represents the second cornerstone of the proposal. ${ }^{58}$ Lastly, the Regulation acknowledges that "the ability to port data without hindrance is a key facilitator of user choice and effective competition." 59 Hence, the Regulation entrusts the European Commission to encourage and facilitate the development of self-regulatory codes of conduct, in order to define guidelines on best practices in facilitating the switching of providers and to ensure that they provide professional users with sufficiently detailed, clear and transparent information before a contract for data storage and processing is concluded. ${ }^{60}$ Pursuant to Article 6, these guidelines should take into account: (a) best practices for facilitating the switching of service providers and the porting of data in a structured, commonly used and machinereadable format including open standard formats where required or requested by the service provider receiving the data; (b) minimum information requirements to ensure that professional users are provided, before a contract for data processing is concluded, with sufficiently detailed, clear and transparent information regarding the processes, technical requirements, timeframes and charges that apply in case a professional user wants to switch

\footnotetext{
${ }^{57}$ Regulation on a framework for the free-flow of non-personal data (n 13) Article 4.

${ }^{58}$ Regulation on a framework for the free-flow of non-personal data (n 13) Article 5.

${ }^{59}$ Regulation on a framework for the free-flow of non-personal data (n 13) Recital 29.

${ }^{60}$ Regulation on a framework for the free-flow of non-personal data (n 13) Article 6.
} 
to another service provider or port data back to its own IT systems; (c) approaches to certification schemes that facilitate the comparison of data processing products and services for professional users to facilitate the comparability of those products and services; (d) communication roadmaps taking a multi-disciplinary approach to raise awareness of the codes of conduct among relevant stakeholders.

The legislative initiative at issue is not immune from criticism. Article 6 creates a new right of business-to-business data portability, similar to the right provided to personal data by Article 20 of the GDPR; however the distinction between personal and non-personal data is far from straightforward. Indeed, since the scope of the latter depends on the former, it would be necessary to embark on the challenging enterprise of delimiting the slippery definition of personal data, which is currently phrased by the GDPR as "any information relating to an identified or identifiable natural person ('data subject')." ${ }^{\prime 1}$ According to the case law of the Court of Justice of the European Union (CJEU), as well as the relevant opinion issued by the Article 29 Working Party, it is clear that whether the personal data "relates to" an "identified or identifiable" individual is ultimately a case-by-case assessment, since these are extremely broad concepts constantly subject to dynamic contextual adaptation. ${ }^{62}$ This interpretative issue is further exacerbated in the current datadriven economy, as IoT and AI advance information de-anonymization and organization hyper-connectivity.

\footnotetext{
${ }^{61}$ GDPR (n 16) Article 4(1). Article 2(2) of Regulation on a framework for the free-flow of non-personal data (n 13) states that, in the case of a data set composed of both personal and non-personal data, the Regulation applies to the non-personal data part of the data set; where personal and non-personal data in a data set are inextricably linked, the Regulation shall not prejudice the application of GDPR.

${ }^{62}$ G. Inge, R. Gellert, N. Purtova, and M. Husovec, 'Feedback to the Commission's Proposal on a Framework for the Free Flow of Non-Personal Data' (2018) <https://ssrn.com/abstract=3106791> accessed 11 September 2018.
} 
Leaving aside these normative concerns, the Regulation demonstrates the strong willingness of EU policy makers to enact a comprehensive form of non-personal data portability able to better meet the competitive need of data-driven markets. Somewhat surprisingly, the European Commission has more recently acknowledged, upon pressure from several stakeholders, that nudging firms towards the adoption of interoperability standards might be more appropriate than horizontal legislation on data sharing in businessto-business relations. ${ }^{63}$ This implies that data trading governance will continue to be based on freedom of contract rather than on hypothetical forms of ownership.

Given these circumstances, APIs are set to take center stage again. Nowadays many firms which hold significant data pools do not leverage their commercial potential or, more often, prevent other companies from accessing them, thereby hindering competition and, ultimately, innovation. ${ }^{64} \mathrm{~A}$ wise first step in tackling this problem effectively could be the encouragement of a systematic use of secured and open APIs. As envisaged by the European Commission, the establishment and employment of these interfaces would require them to be grounded on "stability, maintenance over the lifecycle, uniformity of use and standards, user-friendliness as well as security". ${ }^{65}$ Accordingly, the creation of an EU Support Centre for data sharing has been announced under the Connecting Europe Facility Programme in April 2018. Its main objective will be to assist firms in developing sound APIs with best-practices examples, model contracts and other technical and legal support.

\footnotetext{
${ }^{63}$ European Commission, 'Towards a common European data space' (n 7) 9.

${ }^{64}$ For an economic analysis of the competitive advantaged stemming from the introduction of mandatory data sharing regime in data-driven markets, see J. Graef and J. Prüfer, 'Mandated Data Sharing Is a Necessity in Specific Sectors’ (2018) 103 Economisch Statistische Berichten 298; V. Mayer-Schönberger and T. Ramge, Reinventing capitalism in the age of big data (London: John Murray, 2018), 167; J. Prüfer and C. Schottmüller, 'Competing with big data' (2017) TILEC Discussion Paper No. 2017-006, $<$ https://papers.ssrn.com/sol3/papers.cfm?abstract_id=2918726> accessed 12 September 2018.

${ }^{65}$ European Commission, 'Towards a common European data space' (n 7) 11.
} 


\subsection{Account data portability}

Alongside the general-purpose data portability right enacted through the GDPR, a sectorspecific form of data portability has emerged in the field of payment services, namely the access to account rule (XS2A rule) enshrined in the PSD2, which came into force on 13 January 2018. Pursuant to this new regulatory mechanism, account-servicing payment service providers (ASPSPs), such as banks, shall allow third parties to obtain real-time data relating to customers' accounts and are required to provide access to such accounts by executing payment orders initiated through digital interfaces, on the condition that customers give their explicit consent and that the account is accessible online. ${ }^{66}$ Furthermore, banks are under the obligation to grant such access on a non-discriminatory basis both to payment initiation services (PISs) ${ }^{67}$ and account information services (AISs). ${ }^{68}$ More specifically, any ASPSP shall treat and execute all the payment orders transmitted via a third-party's interface as if they were sent directly by the customer through the banking infrastructure, "without any discrimination other than for objective reasons, in particular in terms of timing, priority or charges vis-à-vis payment orders transmitted directly by the payer." 69

This regulatory intervention aims to address the competitive concerns affecting the retailbanking sector and to nurture FinTech innovation. Notably, by introducing the XS2A rule, the PSD2 marked a crucial step towards the opening of retail payment markets to authorized newcomers, who from now on will have the right to request account information

\footnotetext{
${ }^{66}$ PSD2 (n 17) Articles 64-68.

${ }^{67}$ PSD2 (n 17) Article 66(4)(c).

${ }^{68}$ PSD2 (n 17) Article 67(3)(b).

${ }^{69}$ PSD2 (n 17) Articles 66(4)(c) and 67(3)(b).
} 
without any previous agreements with banks. In this way, the EU aims to promote competition within retail payment markets for the benefit of customers by giving them greater bargaining power and control over their data. Indeed, financial services are awash in data and many financial services and products could be impacted as the use of big data technologies may serve various purposes (from profiling customers and identifying patterns of consumption in order to make targeted offers and personalize products and services, to support finance and risk control activities). ${ }^{70}$

The XS2A rule fosters competition in the banking and financial services industry and opens the path towards an "Open Banking" environment. ${ }^{71}$ The term "Open Banking" is used to denote a foreseen evolution in banking in which consumers are enabled to share their data with third parties through the use of open APIs. However, the implementation process of the data portability right under the GDPR is going to be crucial in determining the success of such regulatory intervention.

Among firms and regulators, APIs are widely believed to be the most reliable instrument for implementing the XS2A rule. ${ }^{72}$ Nevertheless, the process of APIs' definition is a hotly

${ }^{70}$ European Supervisory Authorities, 'Joint Committee Discussion Paper on The Use of Big Data by Financial Institutions’ (2016), 8-10, <https://www.esma.europa.eu/sites/default/files/library/jc-201686_discussion_paper_big_data.pdf $>$ accessed 10 September 2018.

${ }^{71} \bar{G}$. Colangelo and O. Borgogno, 'Data, Innovation and Transatlantic Competition in Finance: The Case of the Access to Account Rule' (2018) Stanford-Vienna EU Law Working Paper No. 35 $<$ https://papers.ssrn.com/sol3/papers.cfm?abstract_id=3251584> accessed 18 September 2018.

${ }^{72}$ See, e.g., Portuguese Competition Authority, 'Technological Innovation and Competition in the Financial Sector in Portugal Issues Paper' (2018), $<$ http://www.concorrencia.pt/vEN/Estudos_e_Publicacoes/Estudos_Economicos/Banca_e_Seguros/Document s/2018\%20-

\%20Issues \%20Paper\%20Technological\%20Innovation\%20and\%20Competition\%20in\%20the\%20Financial $\% 20$ Sector $\% 20$ in\%20Portugal.pdf $>$ accessed 10 September 2018; M. Rosa, 'Achieving Competition in the Financial Sector' (2018) 9 Journal of European Competition Law \& Practice 421, 422; UK Financial Conduct Authority and HM Treasury, 'Expectations for the third-party access provision in Payment Service Directive II' $<$ https://assets.publishing.service.gov.uk/government/uploads/system/uploads/attachment_data/file/630135/E xpectations_for_the_third_party_access_provisions_in_PSDII.pdf $>$ accessed 10 September 2018. 
debated issue, as there is a clear conflict of interest between traditional banking incumbents and FinTech entrants. ${ }^{73}$ Following a public consultation carried out during 2017, the European Commission found that most respondents considered interoperability as a priority for the FinTech market, and believed there was a need for further standardization. ${ }^{74}$ Accordingly, standards and technical specifications should be developed through private ordering initiatives, and the use of global (rather than national or regional) standards should be promoted. Furthermore, most respondents called for the adoption of an open source model where libraries of open source solutions would be made available to developers and innovators.

From a competition policy angle, a major concern stems from the likelihood that banks may design their own APIs in subtly different ways that would make it extremely tricky (and far more expensive) for third party providers to develop services capable of plugging-in with each of them. This would result in a chronic lack of interoperability and would negatively affect consumer welfare. Furthermore, even the PSD2 objectives of commonality and harmonization would be seriously put at risk. For these reasons, allowing a wide range of API standards to be adopted to implement account data portability would pose a serious threat. A minimum level of standardization would instead allow developers to design innovative applications that work efficiently across the market in a harmonized way.

In light of these concerns, the European Commission has started advocating "the development of open standards that increase competition, enhance interoperability and

${ }^{73}$ D. Milanesi, 'A New Banking Paradigm: The State of Open Banking in Europe, the United Kingdom and the United States', TTLF Working Papers n. 29, 75-78, $<$ https://law.stanford.edu/publications/a-new-bankingparadigm-the-state-of-open-banking-in-europe-the-united-kingdom-and-the-united-states/> accessed 10 September 2018.

74 European Commission, 'Public Consultation on FinTech: a more competitive and innovative European financial sector' (2017), 13, <https://ec.europa.eu/info/sites/info/files/2017-fintech-summary-ofresponses en.pdf> accessed 10 September 2018. 
simplify the exchange of and access to data between market players". ${ }^{75}$ Moreover, the European Parliament has expressed its preference for the creation of a set of standardized APIs that undertakings could deploy as a shared language and has highlighted the importance of interoperability for the rise of FinTech innovation. ${ }^{76}$ Accordingly, standardsetting regulatory initiatives are emerging. For instance, the 'Berlin Group' has gained attention among policy makers. The group is an interoperability standards and harmonization initiative led by a pan-European standardization body - which includes banks, payment associations, banking associations, interbank processors, and payment schemes - with the objective of setting open and common standards in the inter-banking domain. Additionally, a task force has been established with the goal of designing an open, common and harmonized European API standard to enable third party providers to access bank accounts under the PSD2. At the same time, the English Consumer and Market Authority, together with the UK Government Open Banking Working Group, is paving the way for an Open Banking environment through the creation of an open API framework that is even more ambitious than PSD2's goals. ${ }^{77}$ Furthermore, the complexity and the risk of inconsistency in the implementation of the XS2A rule led the European Banking Authority to intervene by issuing an Opinion aimed at providing assistance to the private standardization bodies merged across the EU. ${ }^{78}$

\footnotetext{
${ }^{75}$ European Commission, 'FinTech Action plan', (n 20) 7-8.

${ }^{76}$ European Parliament Report on 'FinTech: the influence of technology on the future of the financial sector' (2017), $13 \quad<$ http://www.europarl.europa.eu/sides/getDoc.do?pubRef=-//EP//NONSGML+REPORT+A82017-0176+0+DOC+PDF+V0//EN> accessed 10 September 2018.

${ }_{77}$ Milanesi (n 73) 32.

${ }^{78}$ European Banking Authority, 'Opinion on the implementation of the RTS on SCA and CSC' (2018), $3<$ https://www.eba.europa.eu/documents/10180/2137845/Opinion+on+the+implementation + of + the + RTS + on $+S$ $\underline{\mathrm{CA}+\text { and }+\mathrm{CSC}+\% 28 \mathrm{EBA}-2018-\mathrm{Op}-04 \% 29 \text {.pdf }>}$ accessed 10 September 2018.
} 
The implementation process of the XS2A rule makes it abundantly clear how challenging and troublesome ensuring the effectiveness of data sharing within an industry can be, especially when conflicting interests are at stake.

The EU effort to establish a sound legal framework for data sharing within financial markets has drawn the attention of several other countries, which have begun to follow the European route. The Canadian Competition Bureau, for instance, has invited policy makers to encourage open access to systems and data through APIs $;{ }^{79}$ it has stated that regulators should encourage the use of technology to facilitate account switching, and the use of APIs to access consumers' portfolio information can help make switching easier. Furthermore, in 2017 Japan amended the Banking Act to promote open innovation enabling FinTech companies to access financial institutions' systems via API connections. Moreover, the Monetary Authority of Singapore has set up an APIs register to serve as the initial landing site for Open APIs available in the Singapore financial industry. Finally, in order to ensure the sharing of users' financial, aggregate and transactional data, Article 76 of the recent Mexican FinTech Law (Ley de Instituciones de Tecnología Financiera) requires financial entities and FinTech institutions to establish APIs to allow, with the prior consent of users, connectivity and access to interfaces developed or managed by other financial entities and FinTech institutions.

\footnotetext{
${ }^{79}$ Canadian Competition Bureau, 'Technology-led innovation and emerging services in the Canadian financial services sector' (2017) <http://www.competitionbureau.gc.ca/eic/site/cb-bc.nsf/eng/04315.html> accessed 10 September 2018.
} 


\subsection{Re-use of government data}

Public undertakings are tremendous collectors of information (e.g. statistics, digital maps, meteorological data, legal information, and so forth). Public sector information (PSI) is acknowledged as a valuable resource for the digital economy both in terms of raw material for data-enabled services and for the more accurate decision-making it provides society. Indeed, the total direct economic value of PSI peaked at a level of 52 billion euros in 2017, and it is expected to increase to 194 billion by $2030 .{ }^{80}$ Allowing such data to be reused for other purposes by private and public undertakings might enable the delivery of new services and products across several sectors of the Internal Market. It would also boost the development of new technologies which rely on the continuous processing of vast amounts of high-quality data-streams. On top of that, policymaking and public administration activity are likely to benefit in terms of efficiency and effectiveness from interaction with technology companies which are leveraging big data.

Given the abovementioned potential of public and publicly-funded data, the European Commission, as part of its Digital Single Market strategy, decided to encourage data reuse and PSI access through a review of the Directive 2003/98/EC. ${ }^{81}$ This legislative initiative has been designed to achieve several objectives through a multi-level effort. ${ }^{82}$ First, it aims at lowering transaction costs related to accessing PSI for small and medium-sized firms.

\footnotetext{
${ }^{80}$ Deloitte, 'Study to support the review of Directive 2003/98/EC on the re-use of public sector information', Study for the European Commission (2017) 385, <https://ec.europa.eu/digital-single-market/en/news/impactassessment-support-study-revision-public-sector-information-directive> accessed 14 September 2018.

${ }^{81}$ European Commission, 'Proposal for a Directive on the re-use of public sector information (recast)' COM (2018) 234 final, as modified by the Council of the European Union on 25 October 2018, 2018/0111(COD).. A similar effort has been undertaken also by other countries. For instance, the Australian Government has recently proposed the introduction of a legislation to improve the sharing, use and reuse of public sector data (Australian Government, 'New Australian Government Data Sharing and Release Legislation', Issues Paper for Consultation (2018) <https://www.pmc.gov.au/resource-centre/public-data/issues-paper-data-sharingrelease-legislation> accessed 24 September 2018).

82 European Commission, 'Towards a common European data space' (n 7) 5.
} 
Second, new categories of data would fall under the scope of the revised Directive, such as those related to public utilities, transport and research. Third, the proposal addresses the problem of excessive first-mover advantages arising from poorly designed public-private arrangements that can ultimately lead to a monopolistic exploitation of PSI by a few players. This risk has been mitigated by extending the range of 're-users' and by providing widespread notice of the availability of PSI. Fourth, a systematic uptake of APIs has been identified as the right instrument to ensure smooth access to dynamic dataflow. ${ }^{83}$

Therefore, in accordance with the overall strategy enacted by the European Commission for a common data space, APIs are also set to play a crucial role in the sharing of publiclyfunded data. In essence, the proposed changes to the Directive aim at speeding up the transition of public sector bodies towards digitally-enabled functionalities and contributing to the creation of a valuable ecosystem around data assets. It is worth highlighting that particular attention has been paid by the Commission to the technical details of API set-up and practical use, as they would need to be based on availability, stability, maintenance over lifecycle, uniformity of use and standards, user-friendliness as well as security. ${ }^{84}$ Moreover, public sector bodies will be entrusted with the task of making data available for access immediately after collection by means of suitable interfaces. To the extent that fundamental high-value datasets are involved, public bodies would be under a strong obligation to systematically adopt suitable APIs. In this respect, the revised Directive

\footnotetext{
${ }^{83}$ European Commission, 'Towards a common European data space' (n 7) 5-6: "Providing access to dynamic data via application programming interfaces is particularly important, as it supports the open data ecosystem, saves time and costs through automation of the download process, and greatly facilitates the re-use of data for a wide range of new products and services. Sharing data via the correct and secure use of application programming interfaces can generate significant added value for different actors of the data value chain. It can also contribute to the creation of valuable ecosystems around data assets whose potential is often unused by data holders."

${ }^{84}$ European Commission, 'Proposal for a Directive on the re-use of public sector information (recast)' (n 81) Recital 28.
} 
explicitly provides that APIs shall be used by public bodies to ensure real-time access to data "in a timeframe that does not unduly impair the exploitation of their economic potential." ${ }^{\circ 5}$ A key element of the regime envisaged in the proposal is that PSI would have to be made available free of charge and, if this should prove unfeasible due to excessive costs, any fee would be limited to the marginal costs. Further, to avoid any clash with personal data protection provisions, the proposal states that anonymization costs could be included in the cost calculation for specific access requests. ${ }^{86}$

Since this legislative initiative is ongoing, it would be premature to draw any conclusions concerning the effectiveness of the proposal. However, such a mixed package based on lower intensity regulatory intervention fully fits in the overall transition strategy towards an API economy. ${ }^{87}$ In this regard, the proposal states that APIs should be supported by clear technical documentation that is complete and available online and, where possible, open APIs should be used: European or internationally recognised standard protocols should be applied and international standards for datasets should be used where applicable. ${ }^{88}$

\subsection{The risk of regulatory inconsistencies}

We have been witnessing a strong regulatory attempt by the European Commission to ensure a comprehensive data sharing environment within the Internal Market through APIs

\footnotetext{
${ }^{85}$ European Commission, 'Proposal for a Directive on the re-use of public sector information (recast)' (n 81) Articles 5(4) and 5(5).

${ }^{86}$ European Commission, 'Proposal for a Directive on the re-use of public sector information (recast)' (n 81) Recital 32.

${ }^{87}$ This trend is starting to be followed at Member States level: e.g., the Italian Digital Authority (Agid) has recently issued two circulars (see the Italian Official Gazette, 20 April 2018, 109) providing for a duty for cloud service providers of the public administration to adopt suitable APIs in order to guarantee adequate levels of interoperability.

${ }^{88}$ European Commission, 'Proposal for a Directive on the re-use of public sector information (recast)' (n 81) Recital 28.
} 
and private ordering solutions. As illustrated above, several regimes have already been put forward throughout a quite limited timespan and others are surfacing, such as in the field of electricity and health-care. ${ }^{89}$ Additional concerns have been voiced with reference to the agriculture and automotive industries, highlighting the fact that new forms of access to invehicle and "smart farming" data are required to prevent anti-competitive effects. ${ }^{90}$ In this regard, it seems that the EU legislature is not tackling the matter consistently. ${ }^{91}$ On one hand, all of these initiatives share a strong reliance on APIs as a key facilitator to ensure a sound and effective data-sharing ecosystem (regardless of the general or sector-specific approach of the single legislative instrument). On the other hand, it is equally true that all of these attempts are inherently different when it comes to both the underlying rationale and practical implementation.

For personal data portability, nothing is stated with reference to the tools and interoperable formats that data holders shall adopt. However, for the account data portability rule the European Commission showed much more care in driving its implementation by market players. Moreover, the on-going standardization experience under the PSD2 has shown how complex and troublesome it could be to ensure a sound and effective adoption of a

\footnotetext{
${ }^{89}$ European Commission, 'Communication on enabling the digital transformation of health and care in the Digital Single Market: empowering citizens and building a healthier society' (Communication) COM (2018) 233 final, 6-7; European Commission, Proposal for a directive of the European Parliament and of the Council on common rules for the internal market in electricity (recast)' COM (2016) 864 final, Recital 36.

${ }^{90}$ S. Wolfert, L. Ge, C. Verdouwa, and M.J. Bogaardt, 'Big Data in Smart Farming - A review' (2017) 153 Agricultural Systems 69; TRL, 'Access to In-vehicle Data and Resources', Report for the European Commission (2017) <https://ec.europa.eu/transport/sites/transport/files/2017-05-access-to-in-vehicle-dataand-resources.pdf $>$ accessed 14 September 2018; Graef and Prüfer (n 64) 300.

91 An additional form of data control has been enshrined in the European Commission, 'Proposal for a Directive of the European Parliament and of the Council on certain aspects concerning contracts for the supply of digital content', $\operatorname{COM}(2015) 634$ final, Article 13(2)(c), under which consumers would be allowed to retrieve all content provided by them and any other data produced or generated through the use of the digital content. Since this provision would only ensure an effective consumer protection in the context of contract termination without recognizing a consumer's right to have their digital content directly transmitted to a new provider, it cannot be defined as a proper form of data portability. Similarly, Colangelo and Maggiolino (n 44) 10; Graef, Husovec, and Purtova (n 15) 24.
} 
data portability rule across an industry, despite continuous oversight by the European Banking Authority. ${ }^{92}$ In this respect, the implementation of the free flow of non-personal data, as well as personal data portability, or the re-use of government data are likely to be even more time-consuming and challenging, given the multifarious interests at stake across the industries covered by the scope of these regimes.

From a comparative perspective, it is worth noting that a general and broad data portability right is also the subject of the Australian Government's recent proposal for the introduction of a new Consumer Data Right, which will be established primarily through amendments to the Competition and Consumer Act (2010) and the Privacy Act (1988). ${ }^{93}$ According to the proposal, as part of the commitment to giving consumers greater control over their data, all customers (both individuals and businesses) will be entitled to exercise the right in relation to the classes of data covered by the right. Further, they will have improved access to their own data in a usable form and be able to direct its secure transfer to trusted third parties. Moreover, the Australian Consumer Data Right will be applied sector-by-sector, following an analysis of the merits of applying the right to different classes of data and data holders. Hence, since types of data may vary between sectors, there will be an industry-specific data-specification process that enables the relevant industry to agree on the types of data that will be covered, as well as mechanisms for transfer and security protocols. Notably, the Consumer Data Right will commence in the banking sector (i.e. Open Banking), followed by the energy and telecommunication sectors.

\footnotetext{
92 Colangelo and Borgogno (n 71) 23-24.

93 Australian Government, 'Consumer Data Right' (2018) <https://treasury.gov.au/consumer-data-right> accessed 24 September 2018. For a brief overview, see C. Beaton-Wells, 'Platform Power and Privacy Protection: A Case for Policy Innovation', (2018) 3 CPI Antitrust Chronicle 32, 37-38. For a comparison with the European GDPR, see S. Esayas and A. Day, 'The Proposed Australian Consumer Data Right: A European Comparison', (2018) 3 European Competition and Regulatory Law Review 187.
} 
Because the specific method chosen for ensuring interoperability and data portability is going to be a crucial element in the success or failure of any regulatory intervention providing for data sharing, a clear standardization-oriented approach is highly recommended. Since several market players and incumbents have a strong commercial incentive to undercut a sound data-sharing regime, policy makers should avoid enacting redundant or contradictory regulations and should oversee the implementation of all regulations. Furthermore, firms and public bodies would face serious difficulties in assessing how to comply with a needlessly confusing legal framework involving data sharing.

\section{Some lessons from antitrust to address data sharing}

From the analysis carried out above, some considerations can be made with regards to the requirements which a thorough regulatory intervention needs to fulfill in order to establish a coherent data governance framework. In particular, a broad range of public interests including personal data protection, innovation and competition policy need to be taken into account and consistently balanced. ${ }^{94}$ Against this background, competition law can provide some useful lessons in designing a sound regulatory legal framework for data governance.

\footnotetext{
${ }^{94}$ Graef and Prüfer (n 64) 300.
} 


\subsection{The limits of competition law enforcement}

Competition policy makers have long been debating the role of antitrust law in facilitating data sharing in order to ensure a level playing field for all undertakings. ${ }^{95}$ In accordance with competition law, access to data can be obtained only in exceptional circumstances, notably those referred to in the essential facility doctrine (EFD). ${ }^{96}$

The EFD belongs within the framework of refusal-to-deal and is based on the idea that a firm that is a monopolist has a duty to share its facilities with everyone asking for access, including competitors. As it provides an exception to the general rule which states that firms, even monopolistic ones, are free to contract by choosing whether and with whom to make a deal, the EFD represents one of the most controversial antitrust issues. Indeed, the provision of a duty to share is likely to create counterincentives to invest due to the limited possibility of securing returns. The EFD, originally developed by US courts throughout the 1980s and then gradually retracted, has gained increasing success in the EU. It now represents the main instrument for addressing intellectual property issues from an antitrust perspective.

The case law of the CJEU has defined a framework of exceptional circumstances under which a refusal to deal might involve anticompetitive conduct. According to the leading case Magill, an undertaking holding an exclusive right may engage in abusive conduct if the following conditions are met: (i) the input protected is indispensable due to the lack of actual or potential substitutes, (ii) the lack of an objective justification for a refusal to share,

95 J. Almunia, 'Competition and personal data protection' (2012) Speech at the Privacy Platform event: Competition and Privacy in Markets of Data $<$ http://europa.eu/rapid/press-release_SPEECH-12-860_en.htm> accessed 16 September 2018.

${ }^{96}$ I. Graef, EU Competition Law, Data Protection and Online Platforms: Data as Essential Facility (Kluwer Law International, 2016), 249-280; G. Colangelo and M. Maggiolino, 'Big data as misleading facilities', (2017) 13 European Competition Journal, 264. 
(iii) the possibility of the facility owner reserving for itself a secondary market through its conduct and (iv) the possibility of such a refusal preventing the appearance of a new product which the intellectual property right owner does not offer and for which there is a potential consumer demand. ${ }^{97}$ Further, in Bronner the CJEU clarified that the first circumstance (i.e. indispensability) involves the existence of legal, technical or economic obstacles so serious that any duplication of the facility is practically impossible or not viable. ${ }^{98}$ Subsequent case law has gradually dismantled both the secondary market requirement (e.g., in IMS the CJEU considered the requirement to be met even if that market was just hypothetical $)^{99}$ and the new product requirements (e.g., in Microsoft it was argued that this condition is also fulfilled by follow-on innovation). ${ }^{100}$

According to the European Commission, there is nothing to prevent competition authorities from applying the EFD in the context of data-driven markets. ${ }^{101}$ However, the exceptional circumstances test appears inherently ill suited for tackling competition concerns in datadriven markets. ${ }^{102}$ Indeed, in regard to the first condition, there is no agreement among scholars whether data may be considered an indispensable asset according to Bronner. While some contributions maintain that accessible data (i.e. open data and data which can be collected with the help of data brokers) should never be considered indispensable, ${ }^{103}$

${ }^{97}$ RTE and ITP v. Commission, Joint Cases C-241/91 P and 242/91 P, EU:C:1995:98.

${ }_{98}$ Oscar Bronner GmbH \& Co. v. Mediaprint, Case C-7/97, EU:C:1998:569.

${ }^{99}$ IMS Health GmbH \& Co. OHG v. NDC Health GmbH \& Co. KG, Case C-418/01, EU:C:2004:257.

${ }^{100}$ Microsoft Corp. v. Commission, Case T-201/04, EU:T:2007:289.

${ }^{101}$ European Commission, 'The free flow of data and emerging issues of the European data economy' (Staff Working Document) SWD (2017) 2 final, 21, accompanying 'Building a European data economy' (n 4). See, also, Commission, 'Online Platforms' (Staff Working Document) SWD (2016) 172 final, accompanying 'Online Platforms and the Digital Single Market' (Communication) COM (2016) 288 final, 12, where it declares that stakeholders stressed that a refusal to grant access to essential commercial data is the utmost problem when it comes to unfair trading practices on online platforms.

102 Colangelo and Maggiolino (n 96) 270-274.

103 J. Drexl, 'Designing Competitive Markets for Industrial Data - Between Propertisation and Access' (2016)

Max Planck Institute for Innovation \& Competition Research Paper No. 16-13. <https://ssrn. 
others stress that a vast array of obstacles may render the replicability of specific datasets by new entrants practically impossible. ${ }^{104}$

Additional practical issues are raised by the third condition, namely the exclusion of effective competition in the secondary market requirement. This circumstance is met only when the undertaking holding the essential input is already marketing in the downstream market and, by denying access, forecloses that market to potential new entrants. Such a condition, however, is absent in many cases of refusal to share data.

Moving to the fourth requirement, i.e. the prevention of the appearance of a new product, its fulfillment in data market contexts is not straightforward. In data-driven markets, firms usually do not know the products or services they might design by using certain data before getting access to that data.

Moreover, even if the EFD requirements were met, compulsory licenses regarding data would be difficult to manage for several reasons, such as the scope of the duty to share in terms of subject matter (i.e. the identification of a well-defined set of data) and time horizon, the definition of terms and conditions for the license, and the compliance with data protection law. ${ }^{105}$

Setting aside the abovementioned hurdles to applying EFD, the scope of the antitrust toolbox is limited by its case-by-case approach. Thus, regulatory interventions seem better suited to tackling data-driven economy core issues. Since each industrial sector has specific

com/abstract $=2862975>$ accessed 16 September 2018; Federal Trade Commission, 'Data Brokers: A Call for Transparency and Accountability' (2014); Executive Office of the President, 'Big Data: A Report on Algorithmic Systems, Opportunity, and Civil Rights?' (2016) 5.

104 A.P. Grunes and M.E. Stucke, 'No Mistake about It: The Important Role of Antitrust in the Era of Big Data' (2015) 14 Antitrust Source 1, 8; Graef (n 96) 271.

${ }^{105}$ Colangelo and Maggiolino (n 96) 274-277. 
needs, regulation can be tailored in order to accomplish coherent data access. Nevertheless, any regulatory initiative is called to solve two main issues. First, the effectiveness of data sharing regulatory interventions is linked to the technical implementation process. Second, if access to datasets must be provided, then it is equally necessary to establish appropriate compensation schemes able to strike a balance between the conflicting interests of data holders and access seekers.

\subsection{The role of standardization}

Despite the several legislative initiatives put forward so far by the European Commission, a clear view as to who should define APIs and how they should define them is still lacking. This is a sensitive issue, as the success of any data sharing regulation is mainly dependent on the way the industry implements technicalities. Indeed, interoperability is a cornerstone for guaranteeing that, throughout the market, all undertakings can benefit from data access regimes.

As the production and delivery of data-enabled services requires many operators in the value chain to cooperate, a European common data space will not reach its full potential without the development of open standardized APIs that enhance interoperability and simplify the exchange of data between market players. So far, the European Commission has encouraged firms all over the Internal Market "to consider using open, standardized and well-documented APIs more broadly. This could include making data available in machinereadable formats and the provision of associated metadata." 106 However, private undertakings are basically free to develop APIs and portability tools to comply with

\footnotetext{
${ }^{106}$ European Commission, 'Guidance on sharing private sector data in the European data economy' (n 14) 9
} 
regulatory requests according to their own business convenience, which might not be aligned with the pro-competition goals of underlying regulations. ${ }^{107}$ Hence, the concern stemming from this scenario is that firms will try to comply in autonomous and nonstandardized ways with new regulatory data sharing obligations, thereby ultimately precluding the free flow of data within the Internal Market. Moreover, since data holders often retain strong commercial incentives to share as little data as possible with third parties, and given that the implementation process of access rules is inherently complex, there is a strong risk that incumbents could systematically develop and adopt APIs that are designed to surreptitiously prevent full interoperability with competitors' interfaces. ${ }^{108}$

The case of account data portability can provide a useful insight into how to prevent these risks as its implementation process is at a more advanced stage compared with other initiatives.

The PSD2 establishes that technical implementation of the XS2A rule must be carried out through a "Level 2 legislative process". Accordingly, the European Banking Authority has been charged with developing five sets of guidelines and six drafts of Regulatory Technical Standards (RTS). The drafting process of RTSs demonstrates how difficult it has been to strike a balance between different interests and goals. Indeed, the initial draft of the RTS published in 2017 raised concerns among FinTech players since it established that the only way to access a customer data was through a dedicated interface provided by the bank. According to critics, such a system would have allowed banks to interfere surreptitiously in the data transfer process, thus hampering the commercial potential of FinTech companies.

\footnotetext{
${ }^{107}$ An attempt to provide some guidance on APIs definition is represented by the digital document issued by the Share PSI network co-funded by the European Commission under the Competitiveness and Innovation Framework Programme, <http://www.w3.org/TR/dwbp/\#useanAPI> accessed 18 September 2018. ${ }^{108}$ Milanesi (n 73) 76.
} 
As a response, later in 2017 the European Commission published an amended version of the EBA's draft RTS and set up a mechanism for direct access to customers' accounts in the case of deficiencies in the dedicated interfaces provided by the bank. ${ }^{109}$ The draft was further amended following the comments drawn up by the EBA. National authorities, upon express reassurance with regards to the functioning of the interface, can exempt incumbents from the contingent direct access mechanism. Moreover, representatives of TPPs would have the opportunity to check the reliability of the banking interfaces and review their quality before any exception was granted. At the end of this complex process, the final version of the RTS was released by the EBA in March 2018. ${ }^{110}$

The next challenge is the definition process of the APIs that will be used by undertakings. There is no agreement among market players whether to create them in a standardized way. Some market players have shown strong aversion to the establishment of standardized APIs, outlining that this could hinder innovation as well as competition by normalizing business opportunities across the market. On the other hand, the functioning of a common data space would be undermined if undertakings were free to adopt their own APIs, conveniently designed according to their own commercial incentives without taking into account overall interoperability needs of the market. However, the European Parliament took a strong stance in favor of the creation of a set of standardized APIs that undertakings

\footnotetext{
109 European Commission, Communication on the intention to endorse, with amendments, the draft Regulatory Technical Standards submitted by the European Banking Authority for strong customer authentication and common and secure open standards of communication in accordance with Article 98(4) of Directive (EU) 2015/2366, C(2017) 3459 final.

110 Commission Implementing Regulation 2018/308 laying down implementing technical standards for Directive 2014/59/EU with regard to formats, templates and definitions for the identification and transmission of information by resolution authorities for the purposes of informing the European Banking Authority of the minimum requirement for own funds and eligible liabilities, (2018) OJ L60/7.
} 
could use as a shared language and highlighted the importance of interoperability for the rise of FinTech innovation. ${ }^{111}$

It is also worth highlighting the UK Open Banking initiative as a noteworthy attempt to safeguard regulatory goals by enacting an array of measures tailored on the PSD2 framework and aimed at mandating the development of a single, open standardized set of APIs for the whole industry. ${ }^{112}$ In fact, after an open consultation and in-depth coordination with other government bodies (such as the Financial Conduct Authority, the Treasury and the Bank of England), the UK Consumer and Market Authority entrusted the nine largest banks with the task of setting an Open Banking Standard together with representatives of stakeholders, consumers and SMEs. ${ }^{113}$

The UK Open Banking initiative also represents the main reference point of the recent Australian reform. Within the proposal to introduce a new Consumer Data Right that ensures a general data portability right for consumers, the Australian Government has chosen the banking sector as the first industry for the application of the new right. With regards to the banking industry data-specification process, the Australian Competition and Consumer Commission (ACCC), in consultation with the Office of the Australian Information Commissioner (OAIC), will develop draft rules for Open Banking, while the Data Standards Body will be responsible for setting technical standards. ${ }^{114}$ Data61 has been appointed as the interim data standards body by the federal government. Data61 is entrusted

${ }^{111}$ European Parliament (n 76) 13.

112 Colangelo and Borgogno (n 71) 25-26.

113 UK Competition and Markets Authority, 'The Retail Banking Market Investigation Order 2017, (2017) $<$ https://assets.publishing.service.gov.uk/media/5893063bed915d06e1000000/retail-banking-marketinvestigation-order-2017.pdf $>$ accessed 18 September 2018.

114 See Australian Government, 'Review into Open Banking: giving customers choice, convenience and confidence' (2017) <https://static.treasury.gov.au/uploads/sites/1/2018/02/Review-into-Open-Banking-_Forweb-1.pdf> accessed 24 September 2018. 
with developing open standards that enable consumers to safely access data about them held by businesses and to direct this information to be transferred via APIs to trusted, accredited third parties of their choice. The ACCC will certify technical Data Standards as meeting the requirements for the right. Australia's four major banks have been tasked with implementing an open banking standard by 1 July 2019, while all other banks will need to comply with these standards by 1 July 2020.

\subsection{Are FRAND terms a solution?}

Another key issue stemming from data sharing regimes is the compensation to which the data holder is entitled in exchange for providing access. In this regard, the European Commission put forward the idea of relying on FRAND terms in the Communication "Building a European Data Economy" as well as in the "FinTech Action plan" as a possible way to set remuneration rules for the data accessed by third parties. ${ }^{115}$

In the realm of intellectual property, these licensing rules have been supported by competition authorities and designed by standard-setting organizations (SSOs). ${ }^{116}$ Basically, standard essential patent (SEPs) holders are requested to license their patents to a standard's implementer on FRAND terms. However, there is no consensus on either the

115 European Commission, 'Building a European Data Economy' (n 4) 13; European Commission, 'FinTech Action plan' (n 20) 7. See also European Commission, 'Towards a common European data space' (n 7) 15, with reference to compensation for data sharing: "different options exist, namely limiting the remuneration to a pro rata recovery of the costs incurred in the production, preservation and dissemination of the data - only exceptionally combined with allowing a fair return on investment - and limiting the remuneration to, at maximum, the costs related to the dissemination of the data, considering that the costs of production and preservation of the data depending on the instant case may have already been covered by other revenue streams. The choice of the option could be linked to the public interest purpose pursued and the specificities of the social need it aims to fulfil."

116 For a brief overview, see G. Colangelo and R. Pardolesi, 'Intellectual Property, Standards, and Antitrust: A New Life for the Essential Facilities Doctrine? Some Insights from the Chinese Regulation', in P. Drahos, G. Ghidini and H. Ullrich (eds), Kritika: Essays on Intellectual Property (Edward Elgar 2017) 70. 
meaning of the acronym or on the conditions and procedures which need to be followed in order to comply with a FRAND commitment. ${ }^{117}$ Given that there are no generally agreedupon tests to determine whether a license does satisfy a FRAND commitment, an impressive wave of disputes has arisen in several jurisdictions.

The European Commission made explicit reference to the Huawei judgment to draw inspiration for establishing a workable framework of obligations to reach a data sharing agreement based on competition law. ${ }^{118}$ In Huawei the CJEU did not provide any guidance on how to determine FRAND terms but, instead, laid out a procedural framework formalizing the stage of a negotiation between potential licensees and licensors aimed at reaching a consensus between the parties on a FRAND license. Both the asset holder and the access seeker are incentivized to comply with the abovementioned procedure because the former will be sheltered from antitrust remedies and the latter will be protected from the threat of injunctions.

However, the CJEU left a number of issues unresolved. Namely, inter alia, the very existence of a dominant position in relation to SEPs, the possibility of applying the framework to non-competing entities, the optimal way to solve all those issues arising from the implementation of the parties' duties (e.g. the right order to follow in scrutinizing the FRAND nature of offers and counter-offers, the timing and basis for counter-offers), and the definition of FRAND terms. Indeed, the European Commission has considered the

117 D. G. Swanson and W. J. Baumol, 'Reasonable and Nondiscriminatory (RAND) Royalties, Standards Selection, and Control of Market Power' (2005) 73 Antitrust L.J. 1.

${ }^{118}$ European Commission, 'The free flow of data' (n 101), 21 and 38; Huawei Technologies Co. Ltd v. ZTE Corp., Case C-170/13, EU:C:2015:477. 
framework still very incomplete and has recently released a Communication with the aim of setting out key principles that foster a predictable framework for SEPs. ${ }^{119}$

The fact that litigation around FRAND terms is widespread globally demonstrates how far from an easy solution for the compensation issue this kind of remedy is. ${ }^{120}$ With regard just to the European landscape, it is worth highlighting that the UK courts in Unwired Planet $v$. Huawei took a different view from that of the CJEU. ${ }^{121}$ Among other things, the judgment stated that only one set of licensing terms can be ultimately considered FRAND in a given set of circumstances and that the different steps set forth by the CJEU do not have to be followed in a strict way (i.e. the initial offer and counter-offer do not necessarily have to be FRAND and the initial offer does not necessarily need to precede the filing of the complaint).

Taking this brief overview of litigation involving FRAND terms into consideration, it is important to evaluate whether relying on such a complex framework could actually prove useful in dynamic data-driven markets or if it will, instead, just give rise to a flood of litigation.

${ }^{119}$ European Commission, 'Setting out the EU approach to Standard Essential Patents', (Communication) $\operatorname{COM}(2017) 712$ final.

${ }^{120}$ For an in-depth analysis on the issue, see, inter alia, J.L. Contreras, T.F. Cotter, S.J. Jong, B.J. Love, N. Petit, P. Picht, 'The effect of FRAND commitments on patent remedies' forthcoming in B. Biddle, J.L. Contreras, B.J. Love, and N.V. Siebrasse (eds) Patent remedies and complex products: toward a global consensus (Cambridge University Press), <https://papers.ssrn.com/sol3/papers.cfm?abstract_id=3248726> accessed 17 September 2018.

${ }^{121}$ High Court [2017] EWHC 711 (Pat), affirmed by Court of Appeal [2018] EWCA Civ 2344. Instead, for the German case law see G. Colangelo and V. Torti, 'Filling Huawei's gaps: the recent German case law on Standard Essential Patents' (2017) 38 European Competition Law Review 12. 


\section{Concluding remarks}

APIs are the technological gateway of the data-driven economy and have been identified as a key enabler of interoperability among private and public undertakings. As the flourishing of highly innovative markets based on IoT and AI is increasingly dependent on a sound data sharing framework, a systematic adoption of open and standardized APIs by firms and developers will be crucial for promoting competition and innovation. The European Commission, as part of its Digital Single Market Strategy, has been working on several data-sharing instruments which, even if different in terms of rationale, scope and competitive impact, share a common reliance on APIs.

The right to data portability enshrined in the GDPR has been praised as a remarkable tool for fostering control rights of individuals as well as boosting competition among data holders. Nevertheless, its potential is hindered by the lack of actual interoperability initiatives driven by regulators, thereby leaving private undertakings fully free to develop their own instruments. Indeed, Microsoft, Google, Twitter and Facebook have already done so with the Data Transfer Project. At the same time, a Regulation to ensure a free flow of non-personal data within the Internal Market has recently been enacted. Despite some normative drawbacks, the initiative clearly relies on suitable APIs as a cornerstone for building up a common data market.

In the meantime, sector-specific data-sharing legislative instruments have surfaced as well. First and foremost, the XS2A rule introduced by the PSD2 represents a compelling regulatory intervention explicitly designed to unlock competition in retail banking through a sector-specific data portability rule. Moreover, its complex implementation process has demonstrated once and for all that, when it comes to data sharing, the technicalities enacted 
by market players are crucial for its success. Finally, the review proposal of the Directive on public sector information aims at completing the picture by fostering reuse and access to publicly funded data. In line with the other initiatives, APIs have been identified as the right tool for ensuring access to dynamic streams of data.

As new sector-specific forms of data sharing regimes seem likely to emerge in the near future, we deem it appropriate to make a call for a more consistent overall regulatory approach which, throughout its implementation process, guides private undertakings coherently, according to the specific needs of each industry. In fact, APIs are a technical instrument with great competitive potential when properly adopted in accordance with standardization initiatives that are able to strike a balance among the many interests involved. In this regard, the lesson learned from the XS2A rule enshrined in the PSD2 and the Open Banking Initiative in the UK may serve as a blueprint for the effective and coherent development of other data sharing instruments or their follow-up implementation measures. ${ }^{122}$

Furthermore, we pointed out that the strategy envisaged by the European Commission can benefit from the experience already gained by competition law in other fields. Accordingly, competition authorities are called upon to oversee the transition towards a European common data space driven by the regulatory intervention of EU policymakers. Since the implementation process of data sharing regimes is complex and time-consuming, all regulators involved are expected to prevent subtle forms of anti-competitive practices that

\footnotetext{
${ }^{122}$ As acknowledged in European Commission, 'Towards a common European data space' (n 7) 11 " [t] $]$ his has been the case in the financial sector where the access to certain bank data, via the use of well designed application programming interfaces, has opened up for a whole new ecosystem of financial services like personalised advice on daily spending patterns, all under the control and management of the financial institutions that would not, otherwise, offer such services."
} 
risk frustrating the economic potential of data portability regimes. In this regard, competition law enforcement might play a residual role by filling the gaps that are likely to emerge from sector-specific frameworks as well as general-scope regulations; this is similar to what has been proposed for other industries in the past (such as the telecommunications sector). ${ }^{123}$

Lastly, the ongoing FRAND saga at the intersection of intellectual property and antitrust shall serve as a warning against excessive expectation on its potential ability to solve future compensation issues arising from hypothetical duties to share data with third parties. Since the meaning of the FRAND acronym is inherently ambiguous, there is a risk that a wide reliance on it would trigger never-ending litigation, thereby driving up transition costs. Thus, benefits and drawbacks of encompassing such commitment within the terms and conditions of standardized APIs need to be carefully evaluated before encouraging its systematic adoption.

${ }^{123}$ D. Geradin and M. Kerf, Controlling Market Power in Telecommunications (Oxford University Press, 2003) 316 . 